Anuario del Instituto de Historia Argentina, vol. 17, nº 2, e055, diciembre 2017.

ISSN 2314-257X

Universidad Nacional de La Plata.

Facultad de Humanidades y Ciencias de la Educación.

Centro de Historia Argentina y Americana

\title{
Raúl Scalabrini Ortiz y su relación con la Unión Cívica Radical (1928-1959)
}

\section{Raúl Scalabrini Ortiz and his relation with the Unión Cf́vica Radical (1928-1959)}

\section{Gonzalo Rubio García}

Universidad de Buenos Aires, Argentina | gonza_rubio@hotmail.com

\section{PALABRAS CLAVE}

Scalabrini Ortiz

Nacionalismo

Historia intelectual

Hipólito Yrigoyen

Unión Cívica Radical

\section{KEYWORDS}

Scalabrini Ortiz

Nationalism

Intellectual history

Hipólito Yrigoyen

Unión Cívica Radical

\section{RESUMEN}

Desde sus primeros escritos, Raúl Scalabrini Ortiz guardó una relación ambivalente con la Unión Cívica Radical (UCR), en especial con Hipólito Yrigoyen y posteriormente con Arturo Frondizi. El artículo analiza las críticas y reivindicaciones que dicho autor realizó -entre el período 1928-1959, años en los que hizo referencia a la temática planteada en sus obras más trascendentales y en diversos artículos periodísticos disponibles en la Biblioteca Personal de Raúl Scalabrini Ortiz- hacia ambos expresidentes radicales y su partido, teniendo en cuenta el contexto de época en que escribió sus observaciones y la incidencia que tuvo la llegada del peronismo en sus publicaciones. Además, se tuvieron en cuenta la postura nacionalista de Scalabrini y el fin ideológico que perseguía su relato, siendo ésta una de las explicaciones que se argumentó para dar cuenta del cambio de postura frente a la figura de Yrigoyen.

\section{ABSTRACT}

From his early writings, Raul Scalabrini Ortiz kept an ambivalent relation with the Unión Cívica Radical (UCR) and especially with Hipólito Yrigoyen and then with Arturo Frondizi. The article analyzes the criticisms the author made -between 1928-1959, years in which he referred to the theme raised in his most transcendental works and various newspaper articles available in Biblioteca Personal de Raúl Scalabrini Ortiz- of both radical presidents and their party, taking into account the context in which he made his observations and the impact that the arrival of peronismo had on his publications. In addition to this, will consider Scalabrin's nationalistic positions and his ideologized historical perspective, being this one of the elements considered as a possible explanation of his changing position towards Yrigoyen. 


\section{Introducción}

Raúl Scalabrini Ortiz, -de ahora en más, Scalabrini- nació en 1898 y era el tercer hijo varón de Ernestina Ortiz y Pedro Scalabrini. Su padre, un italiano que emigró a la Argentina en 1868 como resultado de su actividad política, desarrolló aquí la paleontología y la filosofía siguiendo las doctrinas de Auguste Comte. Sin embargo, a diferencia de Pedro, Raúl eligió el mundo literario para expresar su intelectualidad. Luego de lograr editar su primera obra, La manga (1923), y de escribir varios artículos en Martín Fierro, El Hogar, La Nación, se dedicó a recopilar varias de sus anotaciones y publicar El hombre que está solo y espera, obra trascendental para la sociedad porteña de la década de 1930. Allí, Scalabrini buscó revelar a un público vasto el ser nacional, tarea para la que proveyó las líneas de interpretación sobre la identidad nacional contestando una pregunta hasta ese momento, aparentemente, sin respuesta: ¿Qué es ser argentino? $\stackrel{1}{1}$

El contexto político y social en que su premiada obra -así como las posteriores Política británica en el Rio de la Plata (1940) e Historia de los ferrocarriles argentinos (1940)- llegó a la venta no representa una cuestión menor. La década de 1930 se caracterizó por la revisión que realizaron los individuos de los conceptos que articulaban su ideología, la sociabilidad entre sus pares y el sistema político. El impacto de la caída de Wall Street en 1929 seguido de la crisis social y política a principios de la siguiente década establecieron una ruptura que perturbó las imágenes argentinas construidas, en especial aquellas que mostraban una supuesta excepcionalidad de nuestro país (Terán, 2012, p. 227).

A causa del malestar político y social, el 6 de septiembre de 1930 se produjo un golpe militar que expulsó a Hipólito Yrigoyen del gobierno y apresuró un intento de reunificación entre las facciones de la Unión Cívica Radical. José F. Uriburu -seguidor de las tendencias corporativistas en auge en la Europa de la década de 1920- fue quien intentó cambiar la legislación electoral, sin lograrlo, luego de su efímeramente exitosa toma del poder.

No era menor el clima de época a favor de los grupos autoritarios, pero este se torna insuficiente para explicar el auge del nacionalismo y las tendencias filofascistas. Liberales $\underline{2}$ y conservadores se dividieron entre aquellos que mantuvieron su adhesión a la democracia liberal y quienes se volcaron a las filas del corporativismo. La derecha conservadora, al no poder adaptarse a las reglas políticas impuestas por la democracia de masas, y por su incapacidad para postularse como una respuesta viable frente a la Unión Cívica Radical (UCR), adhirió a la búsqueda de alternativas políticas como el golpismo y el fraude electoral. Dichas concepciones fueron las que permitieron el nacimiento de la “década infame”, tal como la tituló el periodista nacionalista José Luis Torre (1945)ํㅗ. La “infamia del proceso residía en el fraude electoral”, la corrupción en la esfera estatal, la desocupación y el avance de las ideas y procedimientos autoritarios (Terán, 2012, p. 228).

Más allá de estas consideraciones, es importante destacar que el nacionalismo filofascista, al cual pertenecía Uriburu, guardaba un sustrato conservador de tradición liberal. Este grupo aprovechó la crisis de la década de 1930 para hacerse con el poder y retornar al lugar que, según consideraban, les había sido injustamente arrebatado, en especial por las propuestas políticas de los "liberales reformistas” -como Ernesto Quesada- en la época del centenario revolucionario. La evolución del nacionalismo filofascista se vio incentivada por la democratización del sistema político y la irrupción definitiva de las masas en la esfera política, acciones que hicieron tambalear las 
certidumbres de la elite (Tato, 2009, p. 150).

Las restricciones políticas al sistema democrático continuaron bajo el gobierno de Agustín P. Justo (presidente entre 1932 y 1938). Éste se distanció del gobierno de Uriburu y pretendió erigirse en defensor de las instituciones democráticas. Sin embargo, el triunfo electoral "basado en el fraude y la proscripción del radicalismo planteó un problema de legitimidad al nuevo gobierno” (Rapoport, 2000, p. 216). Al no poder obtener consenso para la situación de privilegio de los sectores dominantes recurrió a medidas autoritarias y represivas, aunque en las formalidades las instituciones democráticas siguieron funcionando.

En torno a dichos años, Scalabrini tuvo encuentros y desencuentros con la Unión Cívica Radical (UCR) y sus personalidades más influyentes. Con la agrupación FORJA ${ }^{4}$ realizó publicaciones y conferencias de carácter antimperialista y nacionalista que incluso fueron incorporadas al bagaje político del peronismo tras su llegada al poder. Por esta razón, nos proponemos analizar los puntos de acercamiento y distanciamiento ideológico que tuvo Scalabrini en relación con la UCR y sus figuras más representativas, en especial respecto a Yrigoyen y Arturo Frondizi, teniendo en cuenta el contexto de época en que escribió sus observaciones y la incidencia que tuvo la llegada del peronismo -y su posterior caída- en sus publicaciones. El último punto cobra importancia como consecuencia del intercambio epistolar que mantuvieron Juan Domingo Perón y Scalabrini en torno a la presidencia de Frondizi, ya que disponemos de un rico material documental que nos ayudará a comprender las desconfianzas políticas de nuestro autor en relación al expresidente radical.

Para esta tarea utilizaremos como fuentes documentales aquellos escritos de nuestro autor presentados entre los años 1928 y 1959 -sobre todo aquellos divulgados mediante los Cuadernos de FORJA y la revista Qué sucedió en 7 días- y otros materiales, disponibles en la Biblioteca Personal de Raúl Scalabrini Ortiz, como su correspondencia personal y diversos recortes periodísticos publicados en La Gaceta de Buenos Aires, La Nación, Noticias Graficas, entre otros- en los que se trató la temática planteada. Estamos interesados en analizar el relato que Scalabrini buscó transmitir al público en general, pues fue mediante sus obras de circulación pública que trató de establecer una intervención cultural para cambiar la percepción sobre distintos problemas que aquejaban a la sociedad argentina.

Nuestro autor cumplía la función de intelectual, un término que ha recibido distintos usos desde el último tercio del siglo XIX. Su papel dentro de ese terreno -por ser un hombre de ideas que interpelaba a la opinión pública mediante discursos y ensayos con una misión cultural- estaba recortado por la configuración histórica de su tiempo y por aquellos otros intelectuales con los que Scalabrini dialogaba, y que serán los próximos en ser analizados en este trabajo (Altamirano, 2013, pp.17, 73 y 113-115).

Atentos a la anterior lógica, circunscribimos el tipo de investigación que pretendemos desarrollar dentro del campo de estudios de la Historia intelectual. La referencia a este término como campo no es casual, ya que si bien se "inscribe su labor dentro de la historiografía (...), a veces cruza el límite y se mezcla con otras disciplinas” (Altamirano, 2005, p. 10). Entendemos que los aspectos culturales deben analizarse mediante la historia de las ideas, una parte de la historiografía que busca “comprender las ideas y creencias del pasado”-los conceptos, palabras y representaciones sociales- 
utilizando escritos que restituyan la visión que los seres humanos tenían de su época (Terán, 2012, p.11), pero con la precaución de no caer en anacronismos al momento de leer las fuentes históricas, pues hay conceptos naturalizados en nuestra vida cotidiana -nación, patria, y muchos otros que podrían funcionar como ejemplos- cuyo significado era distinto en el pasado (Chiaramonte, 2013, p. 277 y Bruno, 2011, pp. 5-7).

En relación a la metodología planteada, también debemos tener en cuenta los usos políticos de la historia que se realizaron mediante el revisionismo histórico, tendencia historiográfica a la cual adhirió Scalabrini. Tal como afirmó Chiaramonte (2013), consideramos que los historiadores revisionistas utilizaron la historia para librar una batalla política contra la "historia oficial” y el liberalismo político -aunque diferían en los objetivos y figuras que promocionaban-, y lograron una versión de la historia nacional "no menos parcial que aquella que criticaban” (p. 260). Dicha postura no implica considerar a ese grupo de escritores de forma homogénea, pues representó un fenómeno amplio en el que congeniaban autores con diversas posturas políticas. Si bien la mayoría de los revisionistas compartía la crítica hacia el liberalismo y el rumbo seguido por Argentina tras la Batalla de Caseros (1852), las figuras históricas que reivindicaban no siempre eran compartidas, así como tampoco la idea de nación que guardaban ${ }^{5}$. Por esta razón, tal como afirmó Alejandro Cattaruzza (2003), es adecuado considerarlos como un grupo de intelectuales que procuró intervenir en "la amplia zona de encuentro entre el mundo cultural, incluyendo en él a las instituciones historiográficas, y la política” (pp. 145-146)

En consonancia con el postulado anterior, debemos considerar, incluso, que la cosmovisión de los revisionistas fue cambiando a lo largo de los años, especialmente en relación al nacionalismo, postura política que estuvo muy relacionada a dicho grupo de escritores, aunque no de forma excluyente ${ }^{7}$. En referencia a este tema, si bien no será analizado en profundidad, consideramos que se debe deslindar el camino transitado por muchos historiadores pues han categorizado los distintos tipos de nacionalismo con esquemas simplistas que no han logrado más que confundir el estudio sobre dicha temática ${ }^{8}$. Por esa razón, es prudente seguir las posturas de María Inés Tato (2009, pp. 158 y 162-165) y Cattaruzza (2003, pp. 145-146 y 160), quienes se desentendieron de los esquemas planteados y establecieron los contactos que había entre los nacionalistas, ya que era común en la década de 1930 la proliferación de los "grises ideológicos” y los cambios de actitud política entre los intelectuales.

De cualquier forma, en relación con los lineamientos mencionados, consideramos en primer lugar que Scalabrini tuvo una relación ambivalente con la UCR, en especial con la figura de Yrigoyen (debemos tener en consideración que Scalabrini se asoció a FORJA recién en octubre de 1940, cuando se quitó el requisito de previa afiliación a la UCR para la pertenencia en la agrupación, y renunció en el año 1943). Este criterio se basa en los cambiantes argumentos, muchas veces contrapuestos, que mostró nuestro autor en distintos escritos (de diferentes épocas) sobre el partido. Como veremos, hasta la llegada de Perón a la presidencia (1946), nuestro autor osciló entre la pertenencia y la autoexclusión de FORJA. Proponemos, además, que su débil adhesión al radicalismo respondía a la falta de otro partido con el cual se identificara en su totalidad, cuestión que cambió a partir de 1946. 
Respecto al anterior punto, consideramos que el surgimiento del peronismo obligó a Scalabrini como a muchos otros autores- a tomar una postura respecto al partido y adecuar su relato al nuevo clima político. En este sentido, es esencial analizar los cambios que el relato de nuestro autor tuvo respecto a las figuras de Yrigoyen y Perón, pues allí podremos percibir la utilización política de la historia, la cual no fue ajena a sus escritos.

En cuanto a Frondizi y su relación con Scalabrini y el peronismo, sugerimos que sus ambivalencias en torno a su candidatura presidencial eran muestra de la desconfianza que tenía hacia la UCR. El apoyo intelectual que brindó mediante la revista Qué... podría encontrar explicación por estar proscripto el peronismo, lo que convertía a Frondizi en la figura más aceptable para conducir el país y generar un posible retorno de Perón a la Argentina.

También afirmamos que algunas de las posturas del ala personalista del radicalismo le fueron esenciales para completar su bagaje político en la década de 1930. En este sentido, consideramos que la gran mayoría de las reivindicaciones económicas y políticas de Scalabrini fueron inspiradas por distintas figuras importantes del radicalismo, entre ellas, Yrigoyen, Manuel Ortiz Pereyra y Enrique P. Mosconi. Además tomamos en consideración la influencia de FORJA, agrupación que le sirvió para desarrollar sus ideas mediante la militancia política.

\section{Los primeros escritos contra el radicalismo}

En la década de 1920, cuando el radicalismo gozaba de gran popularidad, nuestro autor se encontraba entre aquellos que no se sentían representados por la UCR. Por esta razón, mediante sus escritos en la columna del diario La Nación, Scalabrini (1928) jugó indirectamente contra algunas de las políticas del gobierno, pero sin apuntar directamente a Yrigoyen. Le preocupaba el aumento de los empleados públicos y la "mala administración”, cuestiones que, sin embargo, eran moneda corriente entre las críticas del ciudadano medio hacia el gobierno. Así, argumentaba que "si se castigara la incuria, pocos habrían de ser los empleados municipales que cobraran sueldo” (p. 7).

Mediante sus críticas periodísticas, Scalabrini (1929) estimulaba el resentimiento del ciudadano porteño hacia la administración gubernamental. Sin embargo, sus argumentos no demostraban un conocimiento cabal de la economía ni de la política del momento, más bien se referían a problemas determinados de la ciudad de Buenos Aires, sobre todo en lo referente a la reacción de los comerciantes frente al abuso impositivo del Estado. El fisco, argumentaba, "ha llegado a ser un enemigo y un perseguidor del contribuyente, sordo a sus quejas, arbitrario en sus resoluciones y perjudicial para los demás y también para sí mismo” (p. 6).

También expresó su posición hacia el radicalismo en El hombre que está solo y espera ([1931] 1951). Allí afirmaba: "los radicales perduraron mientras tuvieron presente la idea de su responsabilidad. El pueblo excusaba las pequeñas incorreciones, el arribismo desaforado, porque dieron al país una cohesión espiritual como jamás había tenido” (p. 91). Como podemos observar, nuestro autor rescataba algunas características del partido como la imposición de una cohesión espiritual, cuestión que era de vital importancia en su ideario. Sin embargo, en la misma obra escribió: "Yrigoyen, ya muy anciano, se mareó con los ochocientos mil votos de su candidatura". La altanería, agregó, lo había hecho perderse: “soberbia era menoscabar en vano al Parlamento; 
soberbia, hacer gala de matonismo en las intervenciones (...) ahora estamos frente a una soberbia peor. El capital extranjero está en el poder” (p. 91). Aquí es claro el principio que motivaba la crítica de Scalabrini, ya que nuestro autor establecía sus fundamentos en una óptica moral que ponía en consonancia con su nacionalismo. Las principales características que aborrecía del gobierno de Yrigoyen hacían referencia a cuestiones más bien culturales en las cuales jugaba un papel importante su incipiente antimperialismo.

En Noticias Gráficas (1931) Scalabrini expuso, sin dejar de lado las posturas irracionalistas que caracterizaban sus escritos, el estado de ánimo de la población de la ciudad de Buenos Aires ante la crisis internacional, los argumentos sobre el golpe de estado en ciernes, las expresiones de malestar respecto al gobierno yrigoyenista, y argumentos a favor a la libertad de expresión -pues según creía, el gobierno era restrictivo en este aspecto-. La ciudad, señalaba, se encontraba "atónita, apagada y meditativa”, advirtiendo que su destino era "sucumbir”, cuestión que ejemplifica el sentir de nuestro autor hacia su entorno social (p. 57).

Las críticas de Scalabrini a Yrigoyen no diferían de aquellas que tenía gran parte de la sociedad hacía al expresidente. La raíz de estos argumentos se encontraba en los ataques que distintos grupos sociales hacían al gobierno radical por abrir las puertas de la política y del empleo estatal a la clase media. A su vez, también debemos tener en consideración que el radicalismo fue un partido cuya historia estaba muy relacionada con los levantamientos violentos, la militancia política y la idea de toma del poder gubernamental. En este sentido, muchas personas reprobaban estas prácticas ya que los retrotraían a períodos de la historia argentina -como el rosista de principios del siglo XIX- en los que el autoritarismo y el personalismo eran moneda corriente ${ }^{\underline{9}}$.

El antiyrigoyenismo que planteaba Scalabrini ([1931] 1951) mostraba una posición contestataria, es decir, una búsqueda de nuevas formas de representación política que tuvieran en cuenta aspectos no racionales, como el "alma del pueblo" que describió en El hombre... y también sus críticas hacia el “materialismo”. Debemos tomar en consideración que nuestro autor realizó sus escritos en una época de crisis social en la que se desarrollaron distintas posturas culturales para intentar cambiar aquel inestable escenario. Criticando al radicalismo, escribió: “Cicatearon la opinión del pueblo, trampearon votaciones, sin que el pueblo contuviera su voracidad y su fullería. Se enriquecieron y se entremezclaron a los terratenientes antiguos y respetados” (pp. 88-89). A su vez -y ésta es quizá una de las afirmaciones más contradictorias en relación con su posterior posición favorable al antimperialismo yrigoyenista-, argumentó que, para el radicalismo, “el país les pertenecía”, por eso "entraron en confabulaciones con los capitales extranjeros" y se hicieron "abogados de empresas, directores de ferrocarriles, accionistas de capital inconfesable” (pp. 88-89).

En el caso de los textos de Noticias Graficas, estos contenían más críticas hacia el gobierno de Yrigoyen que ideas concretas para mejorar o cambiar el sistema. Es probable que esto se haya debido a que Scalabrini tampoco sabía qué dirección seguir políticamente. Sus ideas no eran tan precisas como las que formuló hacia el final de la década de 1930. Pensaba que un cambio social se avecinaba, pero no tenía claro qué características él hubiera querido que tuviera, cuestión que explica su apresurada participación en la revolución del 6 de septiembre de 1930. La incursión en la rebelión del coronel Bosch -como veremos a continuación- fue otro ejemplo de las ideas que entonces tenía nuestro autor: aceptaba el cambio político mediante la lucha armada y entendía que 
un militar podía llegar a ser representante de la sociedad sin ser elegido democráticamente.

\section{El levantamiento del coronel Bosch y la reivindicación de Yrigoyen}

El 6 de septiembre de 1930 se produjo un golpe militar que expulsó a Yrigoyen del gobierno y apresuró un intento de reunificación entre las facciones de la UCR. Poco después de la toma del poder por Uriburu, y en paralelo a la desilusión de distintas vanguardias culturales que habían apoyado el golpe, el presidente de facto hizo explicita su propuesta de rechazo al sufragio universal para legitimar su poder. Su pretendido corporativismo llamaba a que el parlamento fuese ocupado por distintos representantes de los intereses sectoriales de la nación, marginando la elección democrática de los representantes. Sin embargo, para el gobierno, el mayor problema fue "evitar que los radicales regresaran al poder” (Persello, 2007, p. 95); estos fluctuaban entre los diversos intentos de reunificación y la conspiración contra el gobierno militar.

Varios movimientos revolucionarios se fueron desarrollando con diversos objetivos, entre ellos fusilar a los funcionarios de la intervención, llamar a elecciones democráticas y dar el poder de la nación a la Corte. Sin embargo, estos eran desbaratados uno tras otro, como fue el caso de los movimientos insurreccionales en los que participaron los grupos de Amadeo Sabattini -junto a militares, bomberos y policías- o el trunco levantamiento que se dio en Buenos Aires en 1931. Finalmente, en julio de ese año se sublevó Gregorio Pomar con la $9^{\circ}$ infantería de Corrientes y el gobierno comenzó actuar contra los dirigentes radicales confinándolos a la prisión y al exilio.

Los radicales intransigentes estaban convencidos de que el general Agustín P. Justo -por entonces presidente de la nación- iba a responder a los intereses económicos y políticos británicos, por ello prepararon una nueva rebelión para la noche del 28 de diciembre de 1933, momento en que habría en Santa Fe una convención nacional de la UCR. Los rebeldes estaban fraccionados en distintos grupos que atacarían en Santa Fe, Rosario, algunas localidades bonaerenses y Corrientes, cuyo frente tenía al mando el coronel Roberto Bosch. Sin embargo, las autoridades habían sido informadas sobre el movimiento y conocían las intenciones rebeldes, motivo por el cual fracasó el levantamiento y se impuso el estado de sitio en todo el país.

Distintos autores, como Norberto Galasso ([1970] 2008), han afirmado la participación de Scalabrini en el levantamiento del Gral. Bosch, y como pudimos comprobar, esta afirmación debe tomarse como acertada (pp. 155-159). Mediante dicha colaboración, nuestro autor abandonó las críticas periodísticas -escasamente documentadas- hacia los gobiernos fraudulentos para dedicarse al análisis de documentos históricos y así poder explicar la dependencia cultural, económica y política de la Argentina con Inglaterra (Bares, 1961, pp. 21-22.). Este hecho nos parece importante ya que muestra el cambio de opción política que transcurrió Scalabrini en unos pocos años: pasó de simpatizar con el golpe filofascista de Uriburu, a participar -luego de haber sido un acérrimo antiyrigoyenista- de un levantamiento apoyado por grupos radicales personalistas.

Scalabrini dejó constancia de su participación en el levantamiento del coronel Bosch en varios documentos. En una carta dirigida a La Nación (1934a) se indignaba por la declaración del periódico donde se lo acusaba de "haber redactado, mediante paga, el manifiesto de los revolucionarios de la capital”. A esta acusación respondió afirmando: “no puedo decir nada más que 
es muy digno de la envergadura moral de quienes lo concibieron. Pobre causa debe ser la que requiere como arma la calumnia del adversario”. Se debe aclarar, además, que tiempo después, en una nota que escribió para el diario Marcha de Montevideo (1939), Scalabrini aclaró que había sido "revolucionario activo en defensa de la libertad del pueblo bajo la dirección del coronel Bosch”, y agregó, sin ocultar el desprecio al gobierno justista, que esa actuación en las filas revolucionarias radicales le valió “el alto honor de ser desterrado” del país.

También, en el artículo "Los signos son los mismos: como en 1938, la patria renuncia a que sus hijos la defiendan” (1957) de la revista Qué..., aclaró que había redactado los planes y proclamas del movimiento de 1933, al que consideró como "sustancialmente radical”, basado en la “reivindicación y liberación económica” (p. 360)ํㅗㄹ inspiraba, ante todo, en la voluntad de impedir la cesión de los comandos de nuestra economía a Gran Bretaña, que el gobierno del general Justo preparaba bajo variadas formas institucionales” (p. 360).

De todas formas, en la citada carta dirigida al director del diario La Nación (1934a), Scalabrini respondió a las imputaciones que el periódico había publicado a comienzos de 1934 acusándolo de mantener vínculos “con gente de la dictadura uriburista y el comisario Hentier”, denuncia que en dicha misiva nuestro autor rechazó utilizando como argumento el gran número de publicaciones críticas hacia el régimen de Uriburu que había escrito para la revista Noticias Gráficas. Este documento es importante porque allí Scalabrini marcó distancia frente a un periódico para el que anteriormente había escrito diversos artículos. En este período empezó a diferenciar a la sociedad en individuos funcionales a la corona inglesa y los nacionalistas a favor del "pueblo" (Scalabrini Ortiz, 1934c, p. 7; Scalabrini Ortiz, 1935, pp. 22, 23, 25 y 29).

También es importante mencionar que, para 1935, en Señales exponía abiertamente la relación de amistad que guardaba con el coronel Bosch. Afirmaba: "Hablando una tarde, mi amigo, el coronel Bosch me dijo una esperanza: la nueva convicción se templa en la intimidad de las tertulias amistosas”. Respecto a dicha relación, Scalabrini argumentó que le sirvió para entender que había dos clases de hombres dirigentes: los que tienen "un sentido histórico y los que se queman en la molicie de todos los días” (p. 29).

La participación de Scalabrini en esa fallida revolución fue uno de los motivos por los cuales debió abandonar el país en 1933플 . Consideramos que los sucesos transcurridos en la década del 30 -el fraude político, la incidencia del imperialismo inglés, entre otros- sumados al exilio político que vivió, lo hicieron rescatar la figura de Yrigoyen y muchas de sus reivindicaciones políticas. Haber sido desterrado de la Argentina -ésta fue una de las opciones que tuvo tras el frustrado levantamiento- por los gobiernos de la década de 1930 ayudó a que se identificase con la figura del caudillo y que se desilusionara de las propuestas autoritarias que proponían algunos inteelctuales como estrategia para nuestro país.

Ya para ese entonces, Scalabrini había cambiado su perspectiva hacia el radicalismo, cuestión que pudimos observar en sus escritos posteriores a 1933. En ellos no faltaban las críticas al gobierno de Uriburu y, como afirmamos, para el año 1934 sus apreciaciones sobre el gobierno de Yrigoyen se alejaban de las que pudimos observar en El hombre... o en Noticias Gráficas. En este sentido, 
argumentaba (1934c) que "[el diario] The Times de Londres presentó a la revolución del general Uriburu como un manotón afortunado del capitalismo norteamericano afincado en la Argentina”. Pero lo que le parecía indudable era que, casi sin excepción, los ministros designados eran allegados a las "grandes empresas yanquis, sobre todo petroleras enemigas irreductibles de Irigoyen (sic), cuya campaña gubernamental decidida había consistido en su campaña contra la Standard Oil” (p. 7). Incluso, Scalabrini (1934c) comparó al expresidente radical con un líder mesiánico al señalar que "como Mahoma supo, en fin, hacerse querer y seguir por su pueblo a tal punto que ya muerto él, su nombre era un símbolo”. Estar con Yrigoyen, afirmó, significaba “estar sentimentalmente con el pueblo" (p. 3).

Ahora bien, a pesar de esta consideración favorable, Scalabrini aún guardaba ciertas críticas hacia el líder radical. Así, por ejemplo, nuestro autor subrayó el error en que habría incurrido "el presidente Yrigoyen al no disolver el Congreso y llamar a nuevas elecciones” para evitar el golpe de Uriburu. La ley, afirmaba, se transgredía constantemente cuando la transgresión favorecía a los intereses extranjeros. Se preguntaba: “¿por qué no transgredirla en defensa de los sagrados intereses de la Nación y del pueblo argentino?” (Scalabrini Ortiz y Dellepiane, 1938a, p. 193). Aclaraba que la ley debía ser inviolable mientras no estuviese en juego la soberanía de la nación, pero Scalabrini creía que "la excesiva puntillosidad legal” de Yrigoyen había generado la "piratería nacional" de los países extranjeros (Scalabrini Ortiz y Dellepiane, 1938a, p. 193). Este ejemplo nos muestra las variaciones que tuvo su ideología, al menos respecto a la figura del expresidente.

Nuestro autor consideraba que contra aquellos que violaban la ley nacional no se podía ser endeble. Por esta razón, propuso una lucha política contra el imperialismo y sus agentes en la que se aplicaran los mismos métodos contrarios a las leyes que imponían los extranjeros contra la soberanía nacional. Indirectamente, Scalabrini proponía que el gobierno actuara fuera de la ley, por lo tanto, consideramos que favorecía los métodos ilegales para imponer sus formas y concepciones, al menos en ciertas circunstancias adversas para el país. Más allá de esa cuestión, debemos tener en cuenta que este tipo de argumentos eran comunes en la década de 1930, cuando los sistemas autoritarios europeos, como el fascismo y el nazismo, se encontraban en auge. Había un descreimiento en los intelectuales de la época -como expresaron los hermanos Irazusta, Cesar Pico o Scalabrini- de los cimientos culturales básicos de la democracia, y una búsqueda de nuevas formas de representación popular (Devoto, y Barbero, 1983, pp. 70-71).

Las valorizaciones sobre Uriburu tampoco fueron ajenas a los vaivenes ideológicos de Scalabrini. En sus últimos años de vida victimizó al expresidente militar y afirmó que bajo la presidencia de Yrigoyen, la "FUBA organizaba actos en favor de la libertad”, los comunistas acusaban a Yrigoyen de fascista, “La Fronda hablaba descaradamente de los grandes negociados y los robos”, mientras que La Nación y La Prensa, “con esa insidia solemne que los caracteriza, daban resonancia a la bullanguería callejera” (Scalabrini Ortiz, 1958c, p. 606). Así, continuó, se formó el ambiente que "perturbó a algunos jefes del ejército e hizo salir de sus casillas al general Uriburu, que fue inmediatamente rodeado por los títeres que obedecían a los dedos del correspondiente Mac Laren”. Según consideraba, detrás del conflicto estaban los intereses económicos por el petróleo. Derrocado Yrigoyen, afirmó, "Uriburu fue bloqueado, maniatado y amordazado, no pudo ni elegir su sucesor. Quería que lo fuese Lisandro de la Torre. Tuvo que dejarlo a Justo” (Scalabrini Ortiz, 1958c, p. 
606). Podemos observar que Scalabrini exculpó a Uriburu de los actos políticos que se sucedieron debido a su intervención en la política, y adjudicó al imperialismo -como era usual en sus escritosun protagonismo importante en sus explicaciones.

Con las últimas citas buscamos mostrar la línea de pensamiento que mantuvo Scalabrini desde mediados de la década de 1930 respecto al derrocamiento de Yrigoyen, y exponer la mínima salvedad que hizo del gobierno de Uriburu. En otros escritos, nuestro autor había sido más crítico del papel jugado por el expresidente de facto. Sin embargo, tal como pudimos observar en el anterior ejemplo, Uriburu fue expuesto como una víctima política. Esta idea se hace aún más creíble al considerar sus escritos publicados a finales de la década de 1950, en los cuales afirmaba: "no soy hombre de partido. No me gusta dejarme ceñir en mis opiniones ni en mis actos por las pequeñas ligazones que exigen los compromisos de la disciplina partidaria. Siento sí, profundamente, los problemas generales de la Nación” (1958b, p. 450). Esta cuestión nos marca nuevamente las dudas que tenía con respecto a la política y su adhesión a algún partido -más allá del peronismo-. "No ser hombre de partido" es algo que debe considerarse incluso una salvedad en relación con su persona, un justificativo que le habría permitido apoyar a distintos políticos según sus ideas del momento o, como afirmaba, “los problemas generales de la Nación” (p. 450).

Fuera de la anterior cuestión, según afirmaba Scalabrini, en FORJA -agrupación en la que comenzó a participar hacia mediados de la década de 1930- seguían las ideas nacionalistas que Yrigoyen había planteado como presidente con el objetivo de aportar nuevas formas de exponer la realidad y de señalar un rumbo distinto para la política argentina. Los Cuadernos de FORJA (1942) tenían como fin realizar una "historia de la corrupción" en clave anti imperialista, es decir, poner al descubierto las formas en que las grandes compañías succionaban “ávidamente los veneros más sustanciosos de nuestra riqueza y de nuestro trabajo” y cómo, “con su acción colateral”, enervaban el "carácter de los dirigentes”, corrompían el ambiente político y debilitaban "hasta los impulsos más nobles” (p. 457).

En las publicaciones de dicha agrupación radical, Scalabrini rescató la figura de Yrigoyen -que en 1922 había creado la empresa estatal YPF- y también la de Enrique Mosconi -director de la empresa- por haber impulsado en 1927 una ley que nacionalizaba el subsuelo, la explotación y comercialización de toda clase de hidrocarburos. Sin embargo, esta ley no fue tomada en cuenta, según nuestro autor, por el veto de los políticos conservadores, las compañías extranjeras y la prensa nacional entre 1928 y 1929. Esta cuestión, desde la óptica de Scalabrini, caracterizaba a Yrigoyen como una víctima de las presiones económicas internas y externas a nuestro país (Scalabrini Ortiz y Dellepiane, 1938a, pp. 190-191).

En otra de las publicaciones de FORJA, Scalabrini volvió a rescatar la figura de Yrigoyen, quien había detenido el proyecto sobre el Ferrocarril Central Córdoba, que estipulaba formar una sociedad anónima en la que el gobierno habría de aportar como capital sus líneas de trocha angosta para fusionarse con la empresa ferroviaria que -luego de "inflar" su capital- obtendría la mayoría de las acciones y el control de la empresa. Por la intercepción de Yrigoyen, afirmaba, "la maniobra, prolijamente preparada por los 'financistas' británicos del Central Córdoba, quedó frustrada” (Scalabrini Ortiz, 1938b, p. 308). 
Como mencionamos anteriormente, Scalabrini (1940) analizó las políticas de Yrigoyen, mientras duró su adhesión -meramente formal en 1940- al grupo FORJA. A partir de 1930 reexaminó de manera positiva la figura del expresidente y de sus gobiernos, dado el carácter corrupto que caracterizó a la política de aquellos años. Además, resaltó distintas iniciativas concretas en relación a la defensa de los recursos naturales y a la inclusión de los inmigrantes, posturas que agregó a su bagaje político (Scalabrini Ortiz, 1940, pp. 18, 19, 20). Al respecto, Scalabrini (1941) escribió una carta al director del diario Crítica. Allí figura un párrafo en el que nuestro autor se definió como un luchador de los ideales de la Unión Cívica Radical y se refirió a las acusaciones de fascismo que recaían sobre él en torno a la época de la Segunda Guerra Mundial. Ello quedó expresado a través de las siguientes palabras: "yo creía que mi obra (...) me ponía a cubierto de tan viles suposiciones y que los diez años en que a partir del 6 de septiembre de 1930 luché por los ideales de la Unión Cívica Radical, debían darme, por lo menos, ese poco de respeto”.

La anterior afirmación es relevante para definir las concepciones políticas que Scalabrini tuvo desde finales de la década de 1930. Si bien nunca estuvo afiliado al radicalismo, se identificaba con las posturas político-económicas que definían al partido desde la rama de FORJA. Sin embargo, podemos pensar que su convencimiento no era acabado y así entender por qué, años después, con el auge del peronismo, Scalabrini afirmaría haber encontrado su verdadera representación política en este movimiento. Más allá de esta cuestión, nuestro autor nunca se escindió del acercamiento al radicalismo que tuvo en la década de 1930. Por el contrario, trató con diferentes argumentos de unir ideas y figuras influyentes del partido con la figura de Perón. De esta forma, podemos apreciar el cambio político que en unos pocos años realizó Scalabrini, al menos en relación a las figuras políticas que rescataba.

\section{La conexión entre Yrigoyen y Perón}

A principios de la década de 1940, Scalabrini tuvo que dar por concluido su semanario La Gota de Agua, del cual sólo pudo editar un número, debido a la falta de financiamiento económico. Esta cuestión, sumada a su personalidad -no buscaba ataduras políticas- y a algunas diferencias que tenía con FORJA, las cuales se acentuaron tras el golpe militar del 4 de junio de 1943, lo llevaron a abandonar la agrupación y alejarse de toda actividad militante. Al respecto escribió: "me presento para ratificar mi renuncia indeclinable de afiliado de FORJA y recuperar así mi absoluta independencia de criterio y de acción intelectual y política” (Scalabrini Ortiz, 1943). Esta cuestión nos retrotrae a una de las hipótesis principales del trabajo: la ambivalencia de Scalabrini respecto al radicalismo. Es claro que nuestro autor no estaba convencido de su pertenencia a la agrupación: si bien coincidía con gran parte de sus postulados, tendía a mostrar inseguridades sobre su adhesión política. 
En lo referente al presidente Perón, Jauretche, según pudimos observar en los escritos de Galasso ([1970] 2008), fue mucho más entusiasta que Scalabrini respecto a los cambios que pudiese establecer como naciente figura política de importancia (p. 314). No fue hasta 1944, y con la promesa de nacionalizar los ferrocarriles, que nuestro autor volcó toda su carrera intelectual a favor del peronismo y militó para este partido tratando de conectar sus ideas nacionalistas con la figura de Perón. También intentó dar lugar a una anacrónica relación entre Perón e Yrigoyen que buscaba imponer al primero características del segundo, como si fuese un sucesor ideológico natural.

En Yrigoyen y Perón, identidad de una línea histórica ([1948] 2009), Scalabrini trató de unir los pensamientos de estos dos políticos que, en realidad, tenían más diferencias que similitudes. Sin embargo, la situación política ameritaba dicha relación. Algunos intelectuales forjistas -entre ellos nuestro autor y Jauretche- veían en el caudillo radical y su postura ideológica las bases teóricas de algunas de las políticas que Perón trataba de impulsar. Es probable que hacia mediados de la década de 1940 los forjistas quisieran establecer una relación directa entre Yrigoyen y Perón para engrosar la base partidaria del líder justicialista. De todas formas, además de Yrigoyen, nuestro autor también se refirió a otras figuras de la historia argentina, como Mariano Moreno, para fundamentar ideológicamente al peronismo (Scalabrini Ortiz, 1948, pp. 10 y 14). No sería aventurado, entonces, argumentar que Scalabrini se valió del uso político de la historia para justificar sus apreciaciones respecto a las ideologías contemporáneas y la formación de su pensamiento $\underline{12}$.

A diferencia de las críticas que había argumentado en El hombre..., en la década peronista Scalabrini ([1948] 2009) enalteció las políticas de Yrigoyen y el límite que este habría puesto a la sumisión que nuestro país tenía con Inglaterra. El expresidente -realizando una política que según nuestro autor podría adjudicársele a Mariano Moreno- habría “detenido el avance del colonialismo”, cuestión que, según afirmaba, le había costado su permanencia en el poder y la difamación de los periódicos (pp. 14 y 17).

Según Scalabrini ([1948] 2009), algunos de los conceptos de Moreno parecían “una voz de estímulo para la orientación en que el general Perón” enfocó la reforma constitucional de 1949. Moreno, afirmaba, nos dictó "normas de una clarividencia que sorprende por su estrecho paralelismo con el criterio resolutivo" de Perón (p. 90). Destacaba que dichas ideas, presentes también "en algunos discursos de su hermano Manuel, en algunos párrafos y en algunas intenciones de Dorrego, en el instinto certero de los caudillos federales y en algunos relámpagos de inspiración de Juan Manuel de Rosas”, cayeron definitivamente abatidas por las propuestas “que propiciaba el extranjero en aquel cónclave de constituyentes de 1853 que de ninguna manera expresaba la voluntad del pueblo de la nación Argentina” (p. 91). De esta forma, como mencionamos anteriormente, estableció un paralelismo entre autores de distintas épocas que, según creía, seguían una línea de pensamiento ideológico similar. Este procedimiento metodológico había sido utilizado en sus escritos anteriores al peronismo. Sin embargo, con posterioridad a 1945 amplió el margen de figuras que analizaba comparativamente con Perón.

En la década peronista, Scalabrini ([1948] 2009) se valió de los anacronismos para establecer una continuidad ideológica e histórica que, según argumentaba, empezó con los hombres de la Revolución de Mayo, quienes habían luchado contra "los hombres pudientes” y sus conspiraciones (p. 10), luego continuó con Rosas, el caudillo que había velado por los intereses nacionales 
(Scalabrini Ortiz, 1940, p. 69), siguió con Yrigoyen, protector de la vida y los intereses de los argentinos, y alcanzó su máxima expresión con Perón, a quien posicionó como el principal exponente de una ideología nacional, antimperialista e industrialista (Scalabrini Ortiz, [1948] 2009, p. 8$). \underline{13}$

Además, en un discurso leído en el Ateneo de Estudios Sociales, Scalabrini (1950) profundizó aún más su criterio de conexión entre el peronismo y el yrigoyenismo. No sólo mostró su apoyo al gobierno peronista, sino que mediante su participación en FORJA, afirmó, “desparramó las semillas de la insurgencia nacional que preparó e hizo posible el advenimiento de la revolución justicialista del general Perón” (p. 157). De esta forma buscó inmiscuirse dentro de la construcción del peronismo, al igual que otros militantes como Jauretche, mediante su participación en el radicalismo forjista.

De cualquier forma, la relación entre Yrigoyen y Perón había sido establecida por Atilio García Mellid y Gálvez con anterioridad a la publicación de Yrigoyen y Perón... ; Gálvez había escrito un artículo, publicado en el periódico El pueblo el 13 de agosto de 1944, en el que afirmaba: “el coronel Perón es un nuevo Yrigoyen” (p. 8). De allí a establecer la línea Rosas-Yrigoyen-Perón había un solo paso, pues con anterioridad Gálvez había establecido la relación Yrigoyen-Rosas. De hecho, el autor denostaba en el citado artículo al Congreso, pues -fiel a su filofascismoconsideraba al organismo una traba para el desarrollo de políticas favorables a los obreros. Al respecto, afirmaba que las iniciativas que habían tenido Joaquín V. González e Yrigoyen no prosperaron debido a que las cámaras no las habían tomado en cuenta. Perón, por el contrario, prescindía de la "politequería” del Congreso y daba beneficios a los trabajadores mediante “decretos rápidamente puestos en práctica” (Gálvez, 1944, pp. 8-9).

García Mellid -uno de los radicales fundadores de FORJA en 1935-, en su libro Montoneras y caudillos en la historia Argentina ([1946] 1985), realizó un análisis sobre la conciencia histórica nacional poniendo el eje en el pueblo como sujeto y centro de la historia. Allí, delineó un esquema en el cual distintos autores, sucesos y gobiernos habrían respondido a los intereses nacionales, mientras que otros habrían sido parte de la "oligarquía” y sus pretensiones por someter a los “argentinos”. (pp. 26-27, 30-31, 56 y 58). El autor consideraba que la historia había sido escrita por los “liberales” y “unitarios” de la "ilustración” que con la intención de defender la "historia oficial” habían luchado contra la "justicia verdadera” por la que peleaban los “caudillos” representados por Juan Manuel de Rosas, Yrigoyen y Perón, según la época que el autor citara. Historiadores como Ernesto Quesada o Estanislao Zeballos, afirmaba, habían buscado desarmar la "historia oficial" mitrista de índole eurocentrista, característica que incluso había compartido "un historiador de mentalidad oligárquica como Emilio Ravignani” (García Mellid, [1946]1985, pp. 11, 27, 31, 37, 43, 56 y 63).

En su esquema, liberalismo y positivismo, ambos de carácter "darwinista”, habían sido expresiones de los intereses sectarios y aristocráticos que expresaban las ideas "cínicas” y faltas de moralidad que sostenían Juan B. Alberdi, Bartolomé Mitre, Domingo F. Sarmiento, Julio A. Roca y Juárez Celman, entre otros. Hasta la llegada de Alem, Yrigoyen y luego de Perón, la "oligarquía”, argumentó García Mellid ([1946] 1985), se consideraba "resguardada en el fortín de sus vericuetos legales”. La "visión del pueblo”, única a pesar de los diferentes contextos de época en que vivieron 
todos los personajes que citaba el autor, habría estado presente en las manifestaciones de sus caudillos. Por esta razón, los períodos históricos cobraban poca relevancia, pues los intereses de los dos supuestos grupos que delineó Mellid para su relato habrían estado determinados desde la Revolución de Mayo (pp. 81, 83, 86, 93-95 y 107-111).

Dicha obra sirve incluso para mostrar cómo se fue dibujando el panorama del revisionismo histórico hacia la década de 1940. Si bien García Mellid y Scalabrini compartían ámbitos con otros intelectuales, hacia el período citado se fueron distanciando las posiciones hasta dividirse en dos grupos a simple vista diferenciados (la "historia oficial” y la "historia revisionista"), pero que en la práctica no eran tan esquemáticos o al menos no lo fueron hasta la caída de Perón en 1955. Si nos atenemos al caso de Ravignani, muchos historiadores como Julio Irazusta habían compartido correspondencia con el investigador $\stackrel{14}{ }$. Sin embargo, al parecer, la búsqueda por diferenciarse de los supuestos “falsificadores de la historia” era más fuerte en aquellos historiadores que adhirieron al peronismo como Scalabrini o Gálvez.

\section{El acercamiento a Frondizi y al peronismo}

Una vez que el peronismo fue proscripto en 1956, la oposición al gobierno provisional centró sus críticas en el proyecto de desperonización -agudizado luego de los fusilamientos de ese año- e “inició estrategias de acercamiento al peronismo”, de las cuales, la más exitosa fue aquella que culminó en el pacto Perón-Frondizi antes de las elecciones de 1958 (Spinelli, 2015, p. 197).

Por esos años, tras la "bendición” política de Perón a Frondizi, Scalabrini ya había comenzado a apoyar desde la revista Qué sucedió en 7 días su candidatura política. Se preguntaba si era fidedigno su accionar político respecto a su apoyo a la independencia nacional en detrimento de la injerencia de capitales extranjeros, o si en cambio se trataba de una cuestión circunstancial con el mero fin de lograr una victoria electoral. Consideraba legítima su posición por haber permanecido de manera constante afiliado al partido radical. En sus palabras, Scalabrini sostenía: "traicionar las ideas que ahora proclama, equivaldría para Frondizi traicionar su propia vida” (Scalabrini Ortiz, 1958b, pp. 450-451). De esta forma, Scalabrini no sólo enaltecía la figura de Frondizi, sino que también le imponía presión política para que respondiera a los planteos que él había asegurado que cumpliría.

Siguiendo esta lógica, Scalabrini buscó evitar el voto en blanco, ya que esta posición, según creía, era votar "implícita y cobardemente por Balbín”. Afirmaba que Frondizi solo podía llegar al poder con el apoyo del voto individual peronista, que servía como garantía de "cumplimiento del mínimo de libertad necesario para rehacer los cuadros” (Scalabrini Ortiz, 1958b, p. 452).

Si bien luego de las elecciones Frondizi obtuvo la victoria, su base de poder era inestable, cuestión que preocupaba a Scalabrini (1958a) debido a la debilidad de su partido y a los problemas económicos y financieros que se avecinaban. Para resolver estos conflictos "sin endeudarse al extranjero", afirmaba, Frondizi debía recurrir a las "últimas reservas de abnegación y patriotismo del pueblo argentino”, las cuales le servirían para enfrentar a sus adversarios políticos.

La estrategia política de Frondizi con Perón, asentada en las ideas de conciliación y unidad nacional, condicionó el proceso político por ser considerada una transgresión a la denominada 
revolución libertadora y, al mismo tiempo, significó una “deslealtad por parte del peronismo” que había imaginado la llegada del expresidente al poder como una puerta para el retorno al Gobierno (Spinelli, 2015, p. 197).

De cualquier forma, las positivas apreciaciones que tenía Scalabrini respecto al expresidente no duraron demasiado. Cuando Frondizi buscó acelerar la llegada de inversiones extranjeras al país, nuestro autor expresó con Perón su desagrado ante dicha medida. La respuesta que recibió expone claramente los pensamientos de ambas figuras. Escribió Perón (1958): “Mi apreciación de la actualidad en la Argentina coincide plenamente con la de usted. Creo, sinceramente, que Frondizi ha traicionado al Pueblo que lo ungió presidente, y que está consumando la proyectada entrega esbozada por el contador Presbich por mandato de Gran Bretaña”.

Mediante estos argumentos de Scalabrini pudimos demostrar que, fuera de su definitivo e innegable apoyo al peronismo, nuestro autor siguió exaltando algunas de las reivindicaciones del radicalismo y de sus figuras más importantes. Aunque debemos hacer una salvedad, pues para él había infiltrados en la UCR que no respondían a las ideas que Yrigoyen había planteado para el partido; ellos no habrían respondido a los verdaderos ideales del radicalismo, sólo habían aprovechado su nivel de popularidad.

\section{Conclusión}

Scalabrini fue un nacionalista particular que a nivel económico defendió posturas estatistas, industrialistas y proteccionistas. Aquellas fueron expresadas sobre todo en sus obras Política británica en el Rio de la Plata e Historia de los ferrocarriles argentinos. Tuvo argumentos a favor de la propiedad y la administración de los servicios, industrias y recursos estratégicos del país por parte del Estado. No sólo creía que daban importantes ganancias económicas a quien los controlara, sino que también consideraba que eran una herramienta para que el país pudiera reafirmar la emancipación política de Europa y también su soberanía nacional. Si las condiciones de sometimiento económico y político no cambiaban, las compañías extranjeras someterían indefinidamente a toda la Nación según su propia conveniencia, razón por la cual se hacía esencial el control estatal en ciertos rubros económicos.

Para Scalabrini, estas ideas formaban parte del bagaje político de algunos sectores del radicalismo y el peronismo. Por esta razón, apoyó al último incluso luego de su proscripción. Con una estrategia política premeditada, Perón fragmentó a la sociedad en peronistas y antiperonistas, división que fue trasladada al ambiente intelectual. El resultado de esta acción fue que autores como los hermanos Irazusta, que habían tenido un gran protagonismo en los años de la década de 1930, perdieron popularidad posteriormente por no sumarse al justicialismo.

En sus últimos años de vida, nuestro autor volvió a realizar publicaciones a favor del peronismo, pero esta vez para bregar por su retorno al poder. Dicha postura pudimos observarla en sus artículos de la revista Qué sucedió en 7días. Scalabrini (1955) creía que las reivindicaciones conseguidas por el partido corrían peligro, por eso argumentó que Perón había sido derrocado por los mismos que habían jugado a favor del imperialismo en la década de 1930, es decir, los “agentes ingleses” (p. 51). Incluso tuvo cierto acercamiento al radicalismo en los años de la presidencia de Frondizi, a 
quien reclamaba que no se desviara de la senda política que había marcado el peronismo, pero con pocas esperanzas al respecto debido a la actitud que el expresidente radical había tomado hacia las empresas extranjeras.

En la división política que establecía no había lugar a matices, Scalabrini no aceptaba la diversidad de pensamientos políticos. Por el contrario, él encasillaba a la población imponiendo sus categorías sin dejar posibilidad para entender la realidad desde distintos esquemas. Por esta razón, figuras como Yrigoyen recibieron juicios contradictorios de su parte. Tal como hemos observado a lo largo del escrito, en la década 1920 Scalabrini fue crítico de su gobierno. Sin embargo, en la década siguiente revirtió esas ideas, ya que consideró como "traidores de la patria” a algunos políticos como Bernardino Rivadavia, mientras que a Yrigoyen lo posicionó en el panteón de los defensores de la soberanía nacional. Incluso utilizó al expresidente radical como un medio para fundamentar ideológicamente al peronismo.

Respecto al radicalismo, en este trabajo hemos podido comprobar que, al menos desde la década de 1930 hasta el surgimiento del peronismo, Scalabrini tuvo un acercamiento a dicho partido y a algunos de sus militantes más conocidos -entre ellos, Jauretche- mediante el antimperialismo que manifestó junto a la agrupación FORJA, reducto intelectual que fue clave para el desarrollo de las positivas apreciaciones que tuvo sobre distintos políticos argentinos como Enrique Mosconi e Yrigoyen, entre otros.

El análisis parcial de la sociedad era un mecanismo propio del revisionismo histórico, similar al utilizado por aquellos escritores a quienes criticaban -como Domingo F. Sarmiento, entre otros-. Los autores que se autodenominaban revisionistas entendían que existía una "historia oficial”, que había sido elaborada por la "oligarquía” y los “enemigos del pueblo argentino”, y otra historia verdadera que era el fundamento en la lucha política contra el imperialismo. Con esta lógica, la historiografía tenía para nuestro autor un fin exclusivamente político. Sus investigaciones basadas en la influencia británica en la política y economía argentina tenían como meta lograr concientizar a la población de las estafas que habían perpetrado los ingleses en connivencia con la "oligarquía”. Así, Scalabrini ([1948] 2009) presentaba distintas líneas históricas de pensamiento con el fin de desenmascarar a quienes, según sostenía, "habían entregado el país” -Mitre y Rivadavia, entre otros- y exaltar a aquellos nacionalistas -Moreno, Rosas e Yrigoyen- que, afirmaba, habían sido excluidos por la "historia oficial" (p. 4).

De todas formas, las obras de Scalabrini fueron esenciales en el mundo intelectual que surgió desde mediados de la década de 1930, pues la imagen histórica que logró formular con sus escritos tuvo gran trascendencia para diversos sectores sociales -no sólo para aquellos que simpatizaban con el nacionalismo, sino también para quienes buscaban comprender los manejos de la política nacional en clave antimperialista y desconfiaban de la rectitud moral y política de la dirigencia conservadora y oligárquica- y muchas agrupaciones políticas -en su gran mayoría ligadas al peronismo-, que incluso reivindican su relato sobre el pasado como una forma de lucha política en el presente. 


\section{Notas}

1 Para este tema, ver: Mutsuki, 2004, p. 198; Galasso, [1970] 2008, pp. 71 y 95; Lindstrom, 1985, pp. 185-187; Cúneo, 1965, pp. 153-154 y Sarlo, 1988, pp. 217-218 y 240-242.

$\underline{2}$ Entendemos que liberalismo fue utilizado para definir y calificar a una variedad muy amplia y heterogénea de ideas, hechos, hombres e instituciones cuyas zonas de compatibilidad no son siempre evidentes. Sin embargo, desde la segunda mitad del siglo XIX, se forjaron formas específicas de hacer política que defendían aquellos que se presentaban como liberales: el sufragio como pieza clave-, las libertades de opinión, reunión y asociación y los mecanismos constitucionales que buscaban controlar el abuso de poder. De cualquier forma, el liberalismo no constituyó un cuerpo estable de ideas ni un lenguaje político uniforme, sino que tuvo manifestaciones y momentos diferentes a lo largo del siglo XIX y el siglo XX. Para este tema, ver Sabato, 2009, pp. 25-28.

$\underline{3}$ Algunas reflexiones de Torres pueden darnos un panorama sobre la percepción que se tenía sobre la época. Dicho autor consideraba que Federico Pinedo, Ministro de Hacienda en el gobierno de Agustín P. Justo, llegó a "ejercitar una verdadera dictadura económica en la el país”, para lo cual, previamente, había sido necesario "descontitucionalizar la República”. Su gestión económica, escribió, había dejado muchos saldos negativos para la República, pero, sin embargo, "había dejado saldos inmensamente favorables para la banca privada, que llegó a substituir a la banca del Estado y a tener el control del mercado de títulos de la Nación”. A su vez, por el camino de la "regulación económica” se llegó al ejercicio de una "dictablanda política más vergonzosa, para el pueblo que se vio obligado a soportarla, que la peor de las tiranías”. Mientras que las tiranías, afirmó, se asientan en la efusión de sangre, las dictablandas, del tipo de la que descontitucionalizó la República desde el año 1932, se asientan en la claudicación moral y en la desvergüenza de los pueblos (Torres, 1945, pp. 46-51).

4 La Fuerza de Orientación Radical de la Joven Argentina (FORJA) fue una agrupación política argentina, fundada el 29 de junio de 1935 y disuelta en 1945, que actuó siguiendo los lineamientos políticos del yrigoyenismo.

$\underline{5}$ En el caso de Ernesto Palacio, por ejemplo, cobraba gran importancia la incidencia de la cultura española en la idea de nación argentina, mientras que para Scalabrini los españoles solo habían significado otra forma de imperialismo similar a la británica. Para este tema, ver Mutsuki, 2004, pp. 186-214; Palacio, 1948, p. 280; Scalabrini Ortiz, 1948, pp. 16-17.

6 Muchos autores han estudiado este tema. Ver Kroeber, 1964, pp. 29-50; Quatrrocchi-Woisson, 1995, pp. 34-35; Cattaruzza, 2003, pp. 143-182; Halperín Donghi, [1971] 2005, pp. 14-20; Stortini, 2006, pp. 245-250; Devoto y Pagano, 2009, pp. 221-255; Terán, 2012, pp. 230-240, entre otros

7 Los nacionalismos y las diferentes ideas de nación que tuvieron los revisionistas recibieron mayor atención en otros artículos: Rubio García, 2016, pp. 63-74; Rubio García, 2017, pp. 80-86.

$\underline{8}$ Los autores que estudiaron este tema pueden ser divididos en cuatro grupos: 1) aquellos que determinaron la existencia de dos tipos de nacionalismo en Argentina, uno "restaurador" y otro “popular” (Navarro Gerassi, 1969, pp. 91-92; Hernández Arregui, 1973, pp. 19-20, 85 у 203; 
Devoto y Barbero, 1983; Buchrucker, 1987; Galasso, [1970] 2008; Spektorowski, 2011, pp. 133195); 2) los que evitaron establecer diferencias entre los nacionalistas y consideraron que los movimientos neutralistas y nacionalistas eran de carácter filofascista y totalitarista (Romero, 1975, p. 238; Halperín Donghi, 2005, pp. 25-28; Finchelstein, 2016, pp. 25-27 y 39); 3) aquellos que plantearon la dicotomía entre el nacionalismo “doctrinario” y el “republicano” (Álvarez Zuleta, 1975, pp. 358-360), y 4) los autores que, aunque tuvieron en cuenta las diferentes ideologías, se desentendieron de las categorizaciones establecidas para analizar dicho fenómeno (Cattaruzza, 2003, p. 160; Cattaruzza, 2007, p. 184; Tato, 2009, p. 158).

9 Para este tema, ver Persello, 2007, pp. 15-33.

10 Ana Jaramillo recopiló los escritos de Scalabrini en los Cuadernos de FORJA y Qué sucedió en 7 días en dos libros que respetan en su totalidad las publicaciones originales: Forjando una nación; Scalabrini Ortiz y Jauretche en la revista Qué sucedió en siete días (2006) y Cuadernos de FORJA (2012).

11 Después de permanecer encerrado en la Isla Martin García, en 1934 Scalabrini se exilió a Europa.

12 Respecto a este punto, otros autores como Ramón Doll o Julio Irazusta usaban la misma metodología. Ver: Quattrocchi-Woisson, 1995, p. 107 y Chiaramonte, 2013, p. 260.

13 En 1937, Scalabrini afirmaba que había sólo tres figuras históricas que habían adquirido el sentimiento "casi místico" del pueblo; “Se llamaban Mariano Moreno, Juan Manuel de Rosas y Hipólito Irigoyen” (p. 19).

14 Ver Irazusta, 1953, p. 3

\section{Bibliografía}

Altamirano, C. (2013). Intelectuales. Notas de investigación sobre una tribu inquieta. Buenos Aires: Siglo XXI.

Altamirano, C. (2005). Para un programa de historia intelectuales y otros ensayos. Buenos Aires: Siglo XXI.

Bares, E. (1961). Scalabrini Ortiz; el hombre que estuvo solo, Buenos Aires: Arturo Peña Lillo.

Bruno, P. (2011). Pioneros culturales de la Argentina. Biografías de una época. Buenos Aires: Siglo XXI.

Buchrucker, C. (1987). Nacionalismo y peronismo. Buenos Aires: Sudamericana.

Cattaruzza, A. (2003). El revisionismo: Itinerario de cuatro décadas. En A. Cattaruzza y A. Eujanián, Políticas de la historia: Argentina 1860-1960 (pp. 143-182). Buenos Aires: Alianza.

Cattarruzza, A., y Rodríguez, F. Prefacio. En R. Scalabrini Ortiz ([1931] 2005), El hombre que está solo y espera (pp. 9-32). Buenos Aires: Biblos, 2005. 
Cattaruzza, A. (2007). Los usos del pasado. La historia y la política argentinas en discusión, 19101945. Buenos Aires: Sudamericana.

Chiaramonte, J. C. (2013). Usos políticos de la historia. Lenguaje de clases y revisionismo histórico. Buenos Aires: Sudamericana.

Cúneo, D. (1965). El desencuentro argentino 1930.1955. Buenos Aires: Pleamar.

Devoto, F. (2002). Nacionalismo, fascismo y tradicionalismo en la argentina moderna, una historia. Buenos Aires: Siglo XXI.

Devoto, F., y Barbero, M. I. (1983). Los nacionalistas. Buenos Aires: Centro Editor de América Latina.

Devoto, F., y Pagano, N. (2009). Historia de la historiografía argentina. Buenos Aires: Sudamericana.

Finchelstein, F. (2016). Orígenes ideológicos de la “guerra sucia”. Buenos Aires: Sudamericana.

Galasso, N. ([1970] 2008). Vida de Scalabrini Ortiz. Buenos Aires: Mar Dulce.

Gálvez, M. (1944). La obra social que desarrolla el coronel perón. En J. D. Perón, El pueblo quiere saber de qué se trata (pp. 7-9). Buenos Aires.

García Mellid, A. ([1946] 1985). Montoneras y caudillos en la historia argentina. Buenos Aires: Eudeba.

Goebel, M. (2003). La Argentina partida: nacionalismos y políticas de la historia. Buenos Aires: Prometeo.

Halperín Donghi, T. (2006). Argentina en el Callejón. Buenos Aires: Ariel.

Halperín Donghi, T. ([1971] 2005). El revisionismo histórico como visión decadentista de la historia nacional. Buenos Aires: Siglo XXI.

Hernández Arregui, J. J. (1973). La formación de la conciencia nacional (1930-1960). Buenos Aires: Plus Ultra.

Irazusta, J. (MCMMLIII). Vida política de Juan Manuel de Rosas a través de su correspondencia. El Advenimiento de Rosas. (tomo I, Primera Parte, 1793-1830). Buenos Aires: Albatros.

Jauretche, A. (1962). FORJA y la década infame. Buenos Aires: Coyoacán.

Kroeber, C. (1964). Rosas y la revisión de la historia argentina. Buenos Aires: Fondo Editor Argentino.

Lindstrom, N. (1985). Scalabrini Ortiz: El lenguaje del irracionalismo. Revista Iberoamericana, 130-131, 13-32. Recuperado http://revistaiberoamericana.pitt.edu/ojs/index.php/Iberoamericana/article/download/3999/4167

Mutsuki, N. (2004). Julio Irazusta: Treinta años de nacionalismo argentino. Buenos Aires: Biblos.

Navarro Gerassi, M. (1969). Los Nacionalistas. Buenos Aires: Editorial Jorge Álvarez. 
Palacio, E. (1948). ¿Se trata de elaborar, al fin, una Constitución para los argentinos? Hechos $e$ Ideas, 54, 280-282.

Perón, J. D. (23 de septiembre de 1958). [Carta a Raúl Scalabrini Ortiz]. Biblioteca personal de Raúl Scalabrini Ortiz (Carpeta Correspondencia R.S.O 1931-1958), Buenos Aires, Argentina.

Persello, V. A. (2007). Historia del radicalismo. Buenos Aires: Edhasa.

Quattrocchi-Woisson, D. (1995). Los males de la memoria. Historia y política en la Argentina. Buenos Aires: EMECE.

Rapoport, M. (2000). Historia económica, política y social de la Argentina (1880-2000). Buenos Aires: Macchi.

Rapoport, M., y Spiguel, M. (2009). Relaciones tumultuosas: Estados Unidos y el primer peronismo. Buenos Aires: Emecé.

Rubio García, G. (2016). El concepto de nación en Scalabrini Ortiz: acercamientos y diferencias de un nacionalista con los intelectuales de su época. Revista de Historia, 17, 56-82. Recuperado de http://revele.uncoma.edu.ar/htdoc/revele/index.php/historia/article/view/1332

Rubio García, G. (2017). Los nacionalismos argentinos: un acercamiento al debate historiográfico en torno a sus figuras de la década de 1930. Historiografías, 13, 74-94. Recuperado de http://www.unizar.es/historiografias/numeros/13/rubio.pdf

Sabato, H. (2009). El pueblo “uno e indivisible”. Prácticas políticas del liberalismo porteño. En L. A. Bertoni y L. De Privitellio (comp.), Conflictos en democracia: la vida política argentina entre dos siglos, 1852-1943 (pp. 25-45). Buenos Aires: Siglo XXI.

Sarlo, B. (1988). Una modernidad periférica. Buenos Aires 1920-1930. Buenos Aires: Nueva Visión.

Scalabrini Ortiz, R. (30 de noviembre de 1928). A través de la ciudad. La Nación, p. 7. Biblioteca Personal de Raúl Scalabrini Ortiz (Caja Archivo 3, Carpeta-Libro 1), Buenos Aires, Argentina.

Scalabrini Ortiz, R. (8 de agosto de 1929). A través de la ciudad. La Nación, p. 6. Biblioteca Personal de Raúl Scalabrini Ortiz, (Caja Archivo 3, Carpeta-Libro 1), Buenos Aires, Argentina.

Scalabrini Ortiz, R. (10 de junio de 1931). La ciudad está triste. Noticias Graficas, p. 57. Biblioteca Personal de Raúl Scalabrini Ortiz (Carpeta 3), Buenos Aires, Argentina.

Scalabrini Ortiz, R. (1934a). [Carta al Director del diario La Nación]. Biblioteca Personal de Raúl Scalabrini Ortiz (Carpeta Correspondencia R.S.O 1931-1958), Buenos Aires, Argentina.

Scalabrini Ortiz, R. (4 de agosto de 1934b). Una nación sin realidad. La Gaceta de Buenos Aires. Biblioteca Personal Raúl Scalabrini Ortiz (Carpeta 7), Buenos Aires, Argentina.

Scalabrini Ortiz, R. (1 de septiembre de 1934c). El nacimiento de la realidad. La Gaceta de Buenos Aires, p. 7. Biblioteca Personal de Raúl Scalabrini Ortiz, (Carpeta 7), Buenos Aires, Argentina.

Scalabrini Ortiz, R. (27 de febrero de 1935). Dos direcciones anónimas de la historia Argentina, Señales. Biblioteca Personal de Raúl Scalabrini Ortiz (Carpeta 7), Buenos Aires, Argentina. 
Scalabrini Ortiz, R. (1937). Las dos rutas de mayo II. Biblioteca Personal de Raúl Scalabrini Ortiz (Carpeta A de anillos), Buenos Aires, Argentina.

Scalabrini Ortiz, R., y Dellepiane, L. (Septiembre de 1938a). Petróleo e imperialismo. En A. Jaramillo (comp.) (2012), Cuadernos de FORJA (pp. 177-225). Buenos Aires: Ediciones de la UNLa.

Scalabrini Ortiz, R. (Noviembre de 1938b). Historia del Ferrocarril Central de Córdoba. En A. Jaramillo (comp.) (2012), Cuadernos de FORJA (pp. 255-321). Buenos Aires: Ediciones de la UNLa.

Scalabrini Ortiz, R. (8 de agosto de 1939). Nota. Marcha. Biblioteca personal de Raúl Scalabrini Ortiz (Carpeta A de anillos), Buenos Aires, Argentina.

Scalabrini Ortiz, R. (1940) Política británica en el Rio de la Plata. Buenos Aires: Reconquista.

Scalabrini Ortiz, R. (18 de junio de 1941). [Carta al Director de Crítica]. Biblioteca Personal de Raúl Scalabrini Ortiz (Carpeta Correspondencia R.S.O 1931-1958), Buenos Aires, Argentina.

Scalabrini Ortiz, R. (Febrero de 1942). Prólogo. En A. Jaramillo (comp.), Cuadernos de FORJA (pp. 457-459). Buenos Aires: Ediciones de la UNLa.

Scalabrini Ortiz, R. (21 de junio de 1943). [Carta a Arturo M. Jauretche]. Biblioteca personal de Raúl Scalabrini Ortiz (Carpeta 4 FORJA), Buenos Aires, Argentina.

Scalabrini Ortiz, R. (1946). Los ferrocarriles deben ser del pueblo argentino. Buenos Aires: Unión Revolucionaria.

Scalabrini Ortiz, R. (1948). El capital, el hombre y la propiedad en la vieja y en la nueva Constitución. Buenos Aires: Reconquista.

Scalabrini Ortiz, R. [15 de septiembre de 1950]. Perspectivas para una esperanza argentina. Biblioteca Persona de Raúl Scalabrini Ortiz (Carpeta A de anillos), Buenos Aires, Argentina.

Scalabrini Ortiz, R. ([1931] 1951). El hombre que está solo y espera. Buenos Aires: Albatros.

Scalabrini Ortiz, R. (23 de octubre de 1955). El gato es mal guardián de las sardinas. El Líder. Biblioteca Personal de Raúl Scalabrini Ortiz (Carpeta 1), Buenos Aires, Argentina.

Scalabrini Ortiz, R. (Noviembre de 1957). Los signos son los mismos. Como en 1938, la patria renuncia a que sus hijos la defiendan. En A. Jaramillo (comp.) (2006). Forjando una nación; Scalabrini Ortiz y Jauretche en la revista Qué sucedió en siete días (pp. 360-365). Buenos Aires: Ediciones de la UNLa.

Scalabrini Ortiz, R. (1958a). [Carta a Juan Domingo Perón]. Biblioteca Personal de Raúl Scalabrini Ortiz (Carpeta Correspondencia R.S.O 1931-1958), Buenos Aires, Argentina.

Scalabrini Ortiz, R. (Febrero de 1958b). Estoy con el partido de los que defienden la tierra argentina contra los intereses extranjeros. En A. Jaramillo (comp.) (2006), Forjando una nación; Scalabrini Ortiz y Jauretche en la revista Qué sucedió en siete días (pp. 446-452). Buenos Aires: Ediciones de la UNLa. 
Scalabrini Ortiz, R. (Julio de 1958c). El esclarecimiento de las conciencias, genuina riqueza del país. En A. Jaramillo (comp.) (2006), Forjando una nación; Scalabrini Ortiz y Jauretche en la revista Qué sucedió en siete días (pp. 604-609). Buenos Aires: Ediciones de la UNLa.

Scalabrini Ortiz, R. ([1948] 2009). Yrigoyen y Perón, identidad de una línea histórica. Buenos Aires: Lancelot.

Spektorowski, A. (2011). Autoritarios y populistas. Los orígenes del fascismo en la Argentina. Buenos Aires: Lumiere.

Spinelli, M. E. (2015). Intelectuales, prensa y política: el sesquicentenario de Mayo en el contexto de la crisis política. En A. Eujanian, R. Pasolini, y M. E. Spinelli (coord.) (2015). Episodios de la cultura histórica argentina: celebraciones, imágenes y representaciones del pasado, Siglos XIX y $X X$. Buenos Aires: Biblos.

Stortini, J. (2006). Los orígenes de una empresa historiográfica: el Instituto de Investigaciones Históricas Juan Manuel de Rosas, 1938.1943. En F. Devoto (comp.), La historiografía Argentina en el siglo XX (pp. 153 a 194). Buenos Aires: Editores de América Latina.

Tato, M. I. (2009). Nacionalistas y conservadores, entre Yrigoyen y la “década infame”. En L. A. Bertoni y L. De Privitellio, (comp.), Conflictos en democracia: la vida política argentina entre dos siglos, 1852-1943 (pp. 149-170). Buenos Aires: Siglo XXI.

Terán, O. (2012). Historia de las ideas en la Argentina. Diez lecciones iniciales, 1810-1980. Buenos Aires: Siglo Veintiuno.

Torres, J. L. (1945). La década infame. Buenos Aires: Editorial de Formación Patria.

Zimmermann, E. (1994). Los liberales reformistas. La cuestión social en la Argentina 1890-1916. Buenos Aires: Sudamericana.

Zuleta Álvarez, E. (1975). El nacionalismo argentino. Buenos Aires: Ediciones La Bastilla. 